\title{
PERENCANAAN PENYEDIAAN DAYA LISTRIK PEMBANGKIT LISTRIK TENAGA HIBRIDA (PLTMH DAN PLTS) DI DESA KAWINDA TO'I MENGGUNAKAN HOMER
}

\section{Planning of Electricity Supply of Hybrid Micro-Hydro and Photovoltaic Power Plant in Kawinda To'i Village using Homer}

\author{
Esi Birahmatihi ${ }^{[1]}$, Abdul Natsir ${ }^{[1]}$, Agung Budi Muljono ${ }^{[1]^{*}}$ \\ ${ }^{[1]}$ Jurusan Teknik Elektro, Universitas Mataram. Jl. Majapahit 62, \\ Mataram, 83125 Lombok, Indonesia \\ ‘* Corresponding author, Email : agungbm@unram.ac.id
}

\begin{abstract}
ABSTRAK
Pembangkit listrik tenaga hibrida (PLTMH dan PLTS) menjadi alternatif penyediaan daya listrik untuk menjangkau daerah terpencil. Pada penelitian ini, perencanaan penyediaan daya listrik dilakukan menggunakan software HOMER (Hybrid Optimization Model for Electric Renewable) untuk menemukan konfigurasi sistem pembangkit listrik tenaga hibrida yang optimal. Konfigurasi sistem dimodelkan terdiri dari turbin air, panel surya, konverter, dan baterai. Di desa Kawinda To'i terdapat PLTMH 200 kW yang sudah tidak beroperasi lagi. Sehingga perlu dilakukan pengaktifan kembali PLTMH. Langkah awal, dilakukan analisis simulasi hujan-debit untuk melihat ketersediaan debit di DAS Oi Marai. Analisis simulasi hujan-debit menggunakan metode pendekatan NRECA karena dilokasi penelitian tidak terdapat AWLR (Automatic Water Level Record). Simulasi pada HOMER menghasilkan konfigurasi sistem yang optimal berdasarkan NPC (Net Present Cost) terendah. Diperoleh konfigurasi sistem berupa kombinasi $600 \mathrm{~kW}$ panel surya, 196,2 kW turbin air, 600 baterai, dan $300 \mathrm{~kW}$ konverter dengan nilai NPC sebesar \$3.123.007 dan COE (Cost Of Energy) sebesar \$0,369/kWh. Energi listrik yang dihasilkan mendapat suplai dari PLTMH sebesar 59\% dan dari PLTS sebesar $41 \%$.
\end{abstract}

Kata kunci: PLTMH, PLTS, PLTHibrida, HOMER, NPC, COE.

\section{ABSTRACT}

Hybrid power plant (micro-hydro and photovoltaic) are an alternative for providing electricity to reach remote areas. In this study, the planning of electricity supply is carried out using HOMER software to find the optimal configuration of the hybrid power plant system. The system configuration modeled consists of a water turbine, solar panels, converter, and battery. In Kawinda To'i village there is a $200 \mathrm{~kW}$ MHPP which is no longer operating. So it is necessary to reactivate MHPP. The first step, a rainfall-discharge simulation analysis is carried out to see the availability of discharge in the Oi Marai watershed. Rain-discharge simulation analysis used the NRECA approach because the research location does not have an AWLR. Simulation using HOMER results that optimal system configuration based on the lowest NPC. The system configuration is a combination of $600 \mathrm{~kW}$ solar panels, 196,2 kW water turbine, 600 batteries, and $300 \mathrm{~kW}$ converter with an NPC value of $\$ 3,123,007$ and a COE of $\$ 0.369 / \mathrm{kWh}$. The electricity produced is supplied by $59 \%$ of MHPP and $41 \%$ of PV.

Key words: MHPP, PV, Hybrid Power System, HOMER, NPC, COE.

\section{PENDAHULUAN}

Pemanfaatan sumber energi terbarukan diharapkan bisa memiliki peran aktif untuk menggantikan sumber energi yang tidak dapat diperbaharui. Pembangunan PLTMH dan PLTS menjadi salah satu solusi yang tepat untuk menjangkau daerah yang belum terjangkau jaringan listrik PLN. Di desa Kawinda To'i sampai saat ini belum mendapat suplai energi listrik dari PLN. Masyarakat hanya mengandalkan PLTMH berkapasitas 200 kW yang beroperasi selama 24 jam. Sejak tahun 2015 PLTMH tidak dapat beroperasi lagi sehingga pada malam hari sebagian besar masyarakat menggunakan lentera untuk penerangan. 
Desa Kawinda To'i memiliki intensitas cahaya matahari yang cukup tinggi yaitu sebesar 4,96 kWh/m²/hari, berpotensi untuk diadakan pembangunan PLTS. Ketika PLTMH dapat kembali beroperasi dengan normal, PLTS dapat diintegrasikan dengan PLTMH menjadi sistem pembangkit listrik tenaga hibrida.

Optimasi desain dan analisis ekonomi teknik dari pembangkit listrik tenaga hibrida off-grid microhydro-photovoltaic array dengan menggunakan bantuan perangkat lunak HOMER 2 versi 2.81 [1]. Hasil simulasi diperoleh konfigurasi system yang paling optimal untuk diterapkan adalah integrasi antara microhydro-photovoltaic array-baterry bank-bidirectional converter. Berdasarkan total NPC terendah sebesar $\$ 146.041$, levelized COE sebesar $\$ 0,525 / \mathrm{kWh}$.

Simulasi menggunakan software HOMER pembangkit listrik hibrida (energi angin dan matahari) memberikan hasil potensi radiasi matahari sebesar 8,073 $\mathrm{kWh} / \mathrm{m} 2 /$ hari dan potensi energi angin sebesar 2,3 m/s. Nilai NPC terendah sebesar \$61.811. Nilai COE terendah sebesar $\$ 0,599 / \mathrm{kWh}$ [2]. Rancangan sistem PLTMH hibrid dengan PLTS, diperoleh konfigurasi sistem pembangkit listrik hibrida yang paling optimal kombinasi PV $18 \mathrm{~kW}$, PLTMH 36,7 kW dengan efiensi turbin 85\%, generator diesel $20 \mathrm{~kW}, 3$ unit baterai 1900 Ah, dan inverter $18 \mathrm{~kW}$ [3].

Optimalisasi sistem mikrogrid hibrida berbasis jarak pagar menggunakan HOMER, menghasilkan konfigurasi sistem yang optimal terdiri dari $1 \times 360 \mathrm{~kW}$ genset SVO $+1 \times 360 \mathrm{~kW}$ genset biogas + baterai $300 \mathrm{kWh}+$ inverter-rectifier $300 \mathrm{~kW}$. Operasi mikrogrid berbasis sistem PLH genset biogas dan genset SVO diperoleh nilai COE $\$ 0,368 / \mathrm{kWh}$, dan NPC (25 tahun operasi) sebesar $\$ 7.750 .000 \quad$ [4]. Optimalisasi Energi Terbarukan pada Pembangkit Tenaga Listrik dalam Menghadapi Desa Mandiri Energi di Margajaya memanfaatkan potensi energi hydro, biomass dan grid dapat melayani $100 \%$ beban per tahun di Margajaya dan memiliki kelebihan listrik, serta dapat dijual ke jaringan dengan jumlah 124.827kWh/tahun. Secara ekonomis, biaya listrik sistem US \$ 0,013/kWh [5]

Simulasi perancangan pemanfaatan energi surya PV-Biogas pada pembangkit listrik Hybrid On-Grid menggunakan software HOMER di Pondok Pesantren
Baiturrahman Ciparay, Kabupaten Bandung menghasilkan nilai COE meningkatkan dari \$0,113 / kWh (PLN) menjadi $\$ 0,186$ / kWh (hybrid on grid). Hasil ini berdasarkan COE masih tergolong mahal, jadi perlu peraturan pemerintah yang memberi subsidi untuk pembangkit listrik bersumber energi terbarukan [6].

\section{Pembangkit Listrik Tenaga Hibrida}

Untuk mengatasi penggunaan energi fosil dalam pemenuhan kebutuhan energi listrik, teknik hibrida banyak digunakan untuk menggabungkan beberapa jenis pembangkit listrik, seperti pembangkit energi matahari, angin, dan diesel, pembangkit energi air dan matahari, pembangkit matahari dan angina [2].

Pembangkit listrik tenaga hibrida didefinisikan sebagai suatu sistem pembangkit listrik yang menggabungkan dua atau lebih pembangkit dengan sumber energi yang berbeda, umumnya digunakan untuk isolated grid, sehingga diperoleh sinergi yang memberikan keuntungan ekonomis maupun teknis. Pembangkit listrik tenaga hibrida merupakan solusi untuk mengatasi terbatasnya listrik di daerah terpencil, pulau-pulau kecil, dan daerah perkotaan [3]

Desa Kawinda To'i memiliki intensitas cahaya matahari yang cukup tinggi yaitu sebesar 4,96 kWh/m²/hari, berpotensi untuk diadakan pembangunan PLTS. Ketika PLTMH dapat kembali beroperasi dengan normal, PLTS dapat diintegrasikan dengan PLTMH menjadi sistem pembangkit listrik tenaga hibrida.

Dalam perencanaan ini dengan memanfaatkan potensi energi desa setempat dengan menggunakan sistem pembangkit hibrida PLTMH dan PLTS. Desain system hibrida menggunakan software HOMER yang merupakan model optimasi pembangkit listrik hibrida yang mensimulasikan pengoperasian sistem selama 8.760 jam dalam setahun berdasarkan biaya NPC (Net Present Cost) yang terendah [7].

\section{METODOLOGI PENELITIAN}

Penelitian dilakukan di desa Kawinda To'i, Kecamatan Tambora, Kabupaten Bima, Provinsi Nusa Tenggara Barat pada bulan November 2019, Januari 2020, dan Juni 2020. PLTMH Oi Marai terletak pada koordinat $\pm 08^{\circ} 06^{\prime} 20^{\prime \prime}$ LS dan $117^{\circ} 59^{\prime} 10$ 'BT. Perencanaan pembangunan 
PLTS terletak pada koordinat \pm 08 06'31" LS dan $118^{\circ} 03^{\prime} 56^{\prime \prime}$ BT.

Kondisi gambaran pemukiman desa Kawinda To,I dan potensi air dari sungai Oi Marai sebagai PLTMH seperti pada Gambar 1, 2 dan 3.

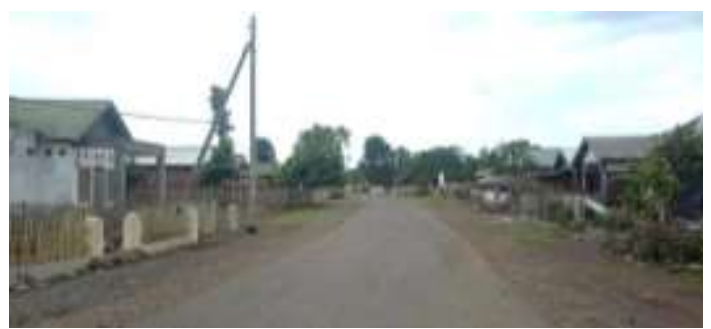

Gambar 1. Pemukiman masyarakat desa Kawinda To'i.

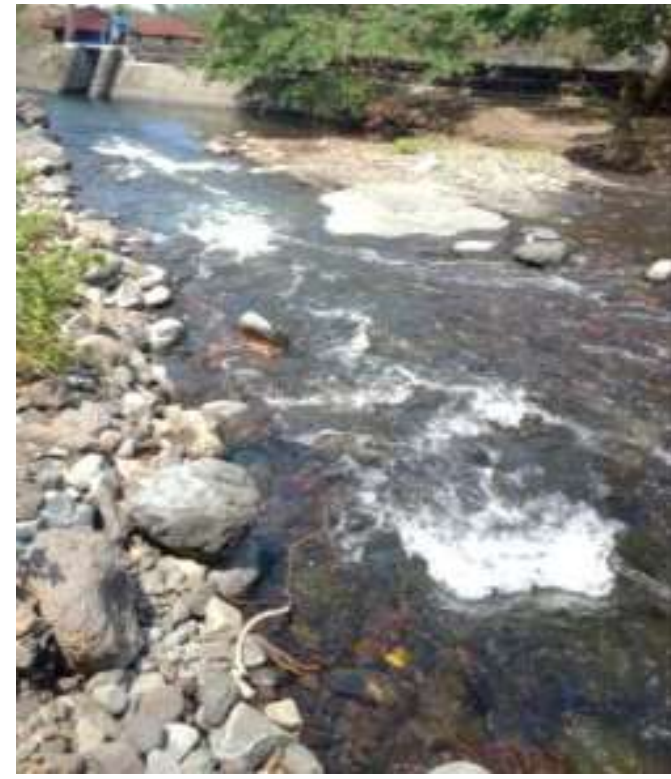

Gambar 2, Bendungan sungai Oi Marai pada bulan kering.

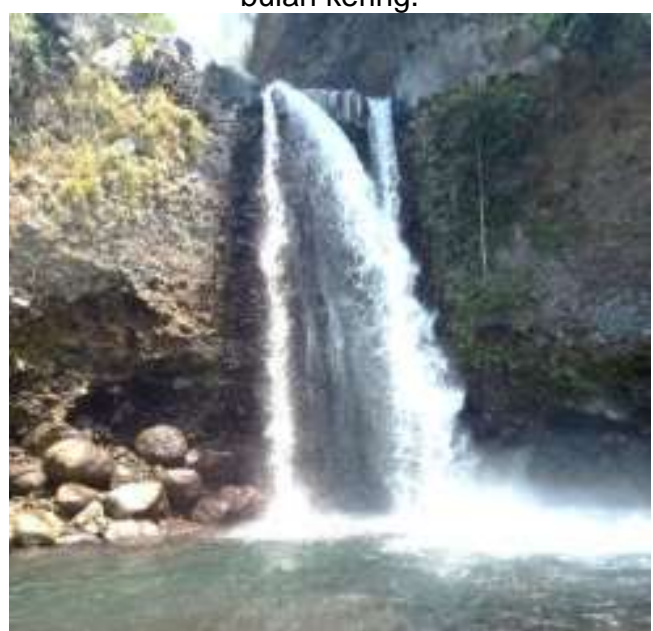

Gambar 3. Air terjun dari bendungan sungai Oi Marai pada bulan kering, berada didepan rumah pembangkit.
Penelitian dilakukan dengan menggunakan data primer dan sekunder. Data primer dilakukan dengan pengukuran secara langgsung di lokasi. Alat penelitian antara lain : Laptop/computer, Software HOMER 2.1.0., GPS (Global Possition System), Kamera, Bola pingpong, Stopwatch, Meteran dan seutas tali.

Pengumpulan data meliputi :

\section{Data Primer}

Data primer berupa data beban harian yang diperoleh berdasarkan hasil wawancara dengan masyarakat desa Kawinda To'i.

\section{Data Sekunder}

Data sekunder berupa data pembangkit listrik tenaga mikrohidro (PLTMH), curah hujan beserta hari hujan, suhu bulanan rata-rata, kelembaban relatif, kecerahan matahari, kecepatan angin rata-rata bulanan, dan potensi radiasi matahari. Data PLTMH diperoleh dari Dinas Pertambangan dan Energi Kabupaten Bima. Data curah hujan beserta hari hujan, suhu bulanan rata-rata, kelembaban relatif, kecerahan matahari, kecepatan angin rata-rata bulanan dan potensi radiasi matahari diperoleh dari Badan Meteorologi, Klimatologi, dan Geofisika Kabupaten Bima.

Gambar 4 menunjukkan diagram metode penelitian yang digunakan.

\section{HASIL DAN PEMBAHASAN}

\section{Beban Listrik}

Simulasi beban listrik bertujuan untuk mengetahui seberapa beban listrik yang bisa ditanggung oleh sistem pembangkit listrik tenaga hibrida. Data beban listrik yang digunakan pada simulasi ini adalah data beban listrik untuk 249 buah rumah, 11 buah kios, 8 buah bengkel, 7 buah mebel, 1 buah kantor Taman Nasional Tambora, 4 buah Sekolah Dasar (SD), 1 buah Sekolah Menengah Pertama (SMP), 1 buah Sekolah Menengah Atas (SMA) Swasta, 50 buah penerangan jalan umum (PJU), 4 buah polindes/posyandu, 1 buah kantor desa, dan 7 buah masjid/mushollah.

Perkiraan karakteristik beban setiap jamnya dihitung berdasarkan jumlah peralatan yang menggunakan energi listrik, seperti pada Gambar 5.

Gambar 5 menunjukkan profil beban listrik di desa Kawinda To'i. Profil beban dibuat dengan asumsi Desa Kawinda To'i 
memiliki listrik dengan pola operasi 24 jam. Data beban listrik yang dimasukkan yaitu

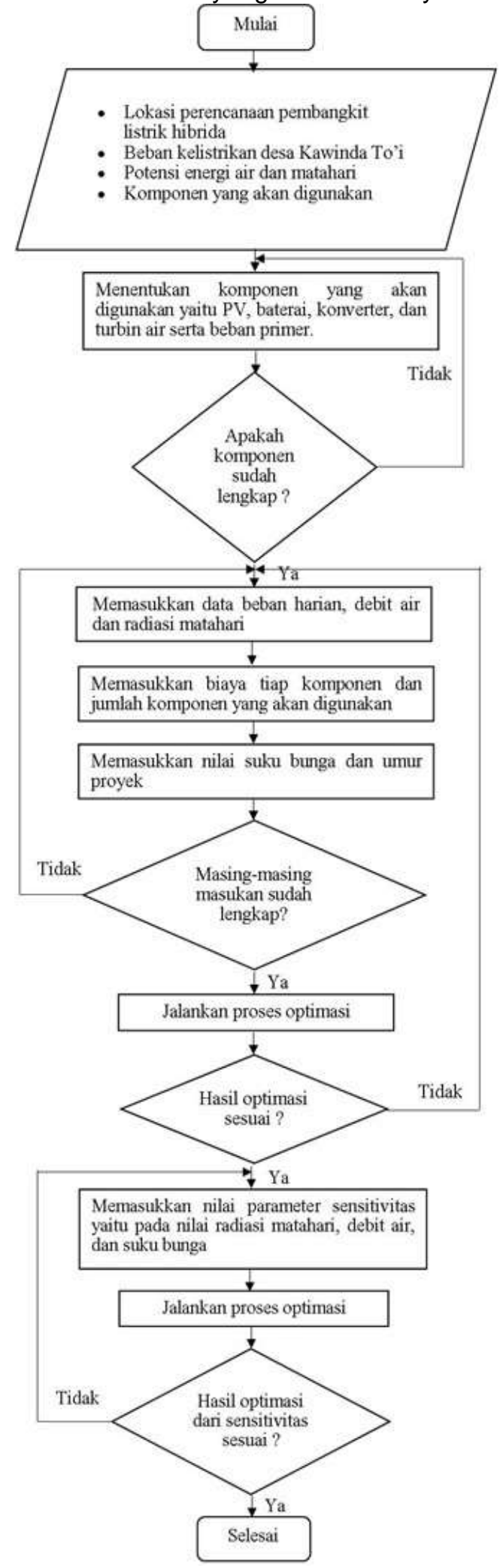

Gambar 4. Diagram alir perancangan.

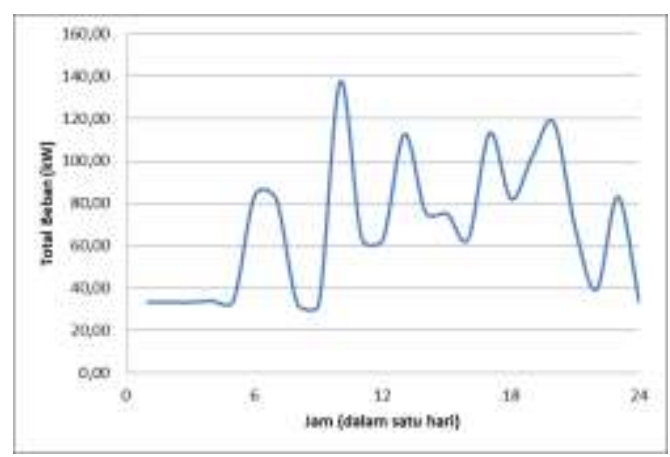

Gambar 5, Profil beban listrik desa Kawinda To'i.

data beban dari jam 00.00-23.00. Beban rata-rata per tahun sebesar $1.631,34 \mathrm{~kW}$, beban puncak yang mungkin terjadi dalam satu tahun sebesar 276,28 kW. Berdasarkan Gambar 9 beban puncak terlihat pada waktu pagi hari yaitu pada jam 09.00 sebesar 137,58 kW. Sedangkan beban terendah terjadi pada jam 07.00 sebesar 32,37 kW.

\section{Kurva Durasi Aliran}

Hasil perhitungan simulasi hujan-debit pada Gambar 6, kemudian ditransformasikan ke dalam bentuk flow duration curve (FDC) seperti pada Gambar 7. Pembuatan FDC dilakukan karena analisis simulasi hujan-debit yang dilakukan dalam rangka melihat ketersediaan debit di daerah aliran sungai Oi Marai untuk pengaktifan kembali PLTMH Oi Marai. PLTMH Oi Marai dibangun berdasarkan ketersediaan debit air sungai sebesar 1.000 $\mathrm{l} / \mathrm{s}$, probabilitas sebesar $50 \%$. Berdasarkan grafik FDC Gambar 7, ini memungkinkan untuk pengaktifan kembali PLTMH Oi Marai karena debit air sungai yang tersedia saat ini cukup, sesuai awal perencanaan pembangunan PLTMH.

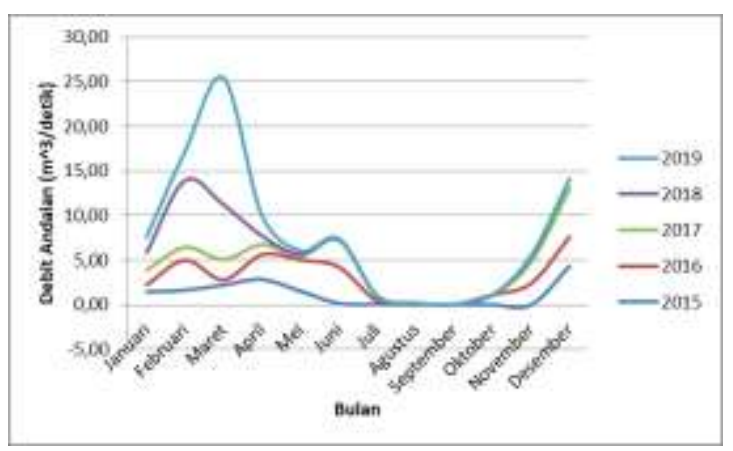

Gambar 6. Debit sungai Oi Marai. 


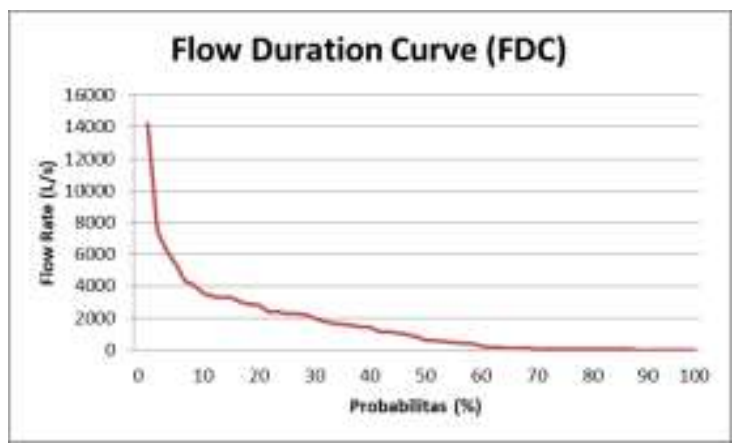

Gambar 7. Kurva durasi aliran.

Berdasarkan lokasi perencanaan pembangunan PLTS pada koordinat $\pm 08^{\circ} 06^{\prime} 31^{\prime \prime}$ LS dan 118 03'56" BT, rata-rata intensitas radiasi matahari bulanan dalam satu tahun dapat dihitung dan diukur secara langsung. Perhitungan didasarkan pada persamaan pada teori dengan waktu matahari nyata (Apparent Solar Time, AST), bidang ekliptik adalah bidang perjalanan bumi ketika ia melintasi matahari, inklinasi dari sumbu polar poros bumi dan sudut deklinasi sudut antara sinar matahari dan garis tegak lurus terhadap sumbu polar dalam bidang sinar matahari, [8]. Hasil perhitungan intensitas radiasi pada Tabel 1

Tabel 1 Hasil perhitungan radiasi matahari di desa Kawinda To'i.

\begin{tabular}{|c|c|c|c|}
\hline No & Bulan & $\begin{array}{c}\text { Intensitas } \\
\text { Iradiasi } \\
\text { Normal } \\
\text { Langsung IDN } \\
\left(\mathbf{k W h} / \mathrm{m}^{2}\right)\end{array}$ & $\begin{array}{c}\text { Indeks } \\
\text { kecerahan } \\
\text { awan }\end{array}$ \\
\hline 1 & Januari & 4,546 & 0,440 \\
\hline 2 & Februari & 4,550 & 0,450 \\
\hline 3 & Maret & 4,935 & 0,500 \\
\hline 4 & April & 4,961 & 0,560 \\
\hline 5 & Mei & 4,775 & 0,580 \\
\hline 6 & Juni & 4,427 & 0,540 \\
\hline 7 & Juli & 4,444 & 0,550 \\
\hline 8 & Agustus & 5,117 & 0,590 \\
\hline 9 & September & 5,582 & 0,620 \\
\hline 10 & Oktober & 5,862 & 0,610 \\
\hline 11 & November & 5,388 & 0,480 \\
\hline 12 & Desember & 4,951 & 0,450 \\
\hline
\end{tabular}

\section{Hasil Optimasi}

Optimasi sistem pembangkit hibrida seperti konfigurasi Gambar 8 untuk radiasi matahari $4,96 \mathrm{kWh} / \mathrm{m}^{2} /$ day, debit air 1.000 $\mathrm{l} / \mathrm{s}$, dan tingkat suku bunga $4,6 \%$ terdiri dari $600 \mathrm{~kW}$ panel surya, 600 baterai bank, 196,2 kW turbin air, dan 300 kW konverter.

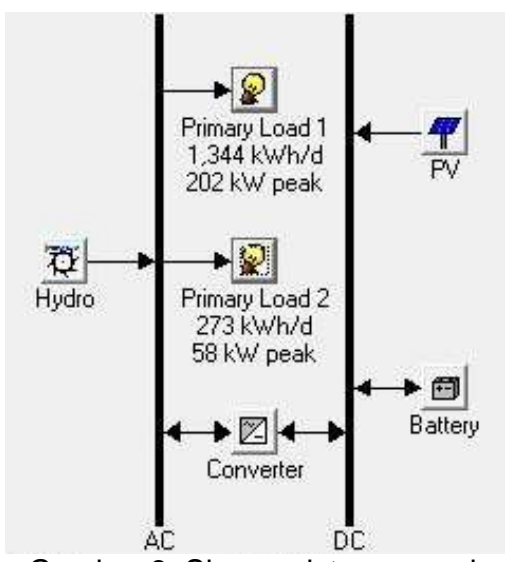

Gambar 8. Skema sistem energi.

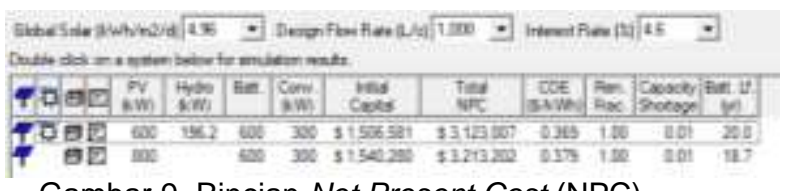

Gambar 9. Rincian Net Present Cost (NPC).

Rincian biaya NPC yang mencakup semua biaya yang dikeluarkan selama proyek berlangsung dapat dilihat pada Gambar 9. Total NPC sebesar \$3.123.007 dan Cost of Energy (COE) $\$ 0,369 / \mathrm{kWh}$. Selama proyek berlangsung, hasil simulasi renewable fraction diperoleh $100 \%$ karena hanya mengandalkan sumber energi yang dapat diperbaharui. Penggunaan bahan bakar tidak dibutuhkan sehingga pada hasil optimasi total fuel bernilai $0 \mathrm{l} /$ year. Biaya terbesar yang harus dikeluarkan selama 25 tahun adalah biaya investasi awal yaitu sebesar \$1.506.581.

\section{Produksi Listrik}

Produksi listrik untuk radiasi matahari $4,96 \mathrm{kWh} / \mathrm{m}^{2} /$ day, debit air $1.000 \mathrm{l} / \mathrm{s}$ dapat dilihat pada Gambar 10.

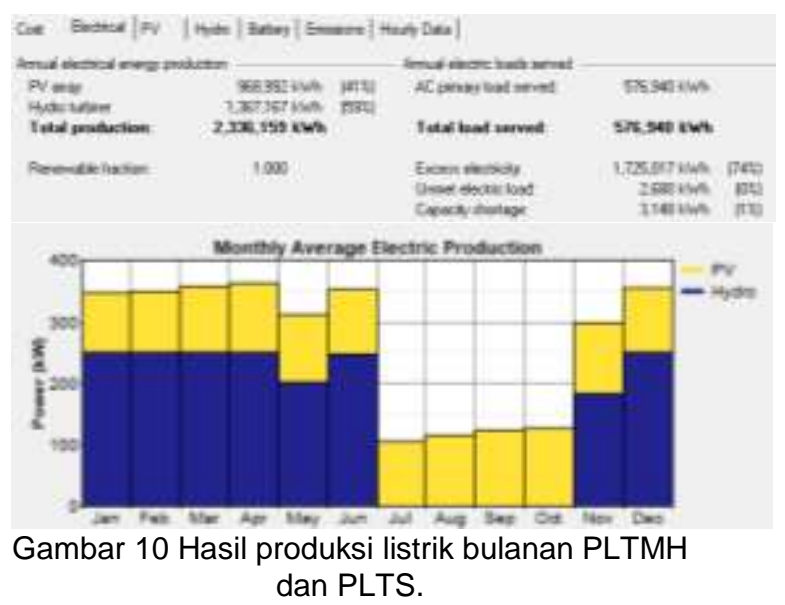


Pada Gambar 10, terlihat bahwa pada bulan November sampai bulan Juni konsumen mendapat suplai listrik dari PLMTH dan PLTS namun pada bulan Juli sampai bulan Oktober konsumen mendapat suplai listrik hanya dari PLTS karena pada bulan tersebut merupakan musim kemarau. Kontribusi panel surya sebesar $41 \%$ atau $968.992 \mathrm{kWh} /$ tahun sedangkan turbin air sebesar 59\% atau 1.367.167 kWh/tahun. Secara keseluruhan sistem menghasilkan energi listrik sebesar 2.336.159 kWh/tahun. Total konsumsi energi listrik oleh beban sebesar $576.940 \mathrm{kWh} /$ tahun.

Excess electricity merupakan kelebihan energi yang dihasilkan sistem, yaitu sebesar 1.725.017 kWh/tahun. Kelebihan energi listrik ini akan disimpan ke baterai untuk kemudian sewaktu-waktu dapat dipergunakan sesuai permintaan beban ataupun pada saat turbin air tidak beroperasi. Sistem ini mampu memenuhi $100 \%$ beban sepanjang tahun dan bahkan menyediakan kelebihan suplai untuk mengantisipasi pertumbuhan beban di masa mendatang.

Unmet load pada sistem sebesar $2.680 \mathrm{kWh} /$ tahun, ini terjadi ketika permintaan beban melebihi persediaan energi listrik yang ada, sehingga beban tidak dapat dilayani oleh sistem.

Capacity shortage atau besarnya kekurangan energi per tahun yang disebabkan menurunnya radiasi matahari dan debit air pada bulan-bulan tertentu yaitu sebesar $3.148 \mathrm{kWh} /$ tahun.

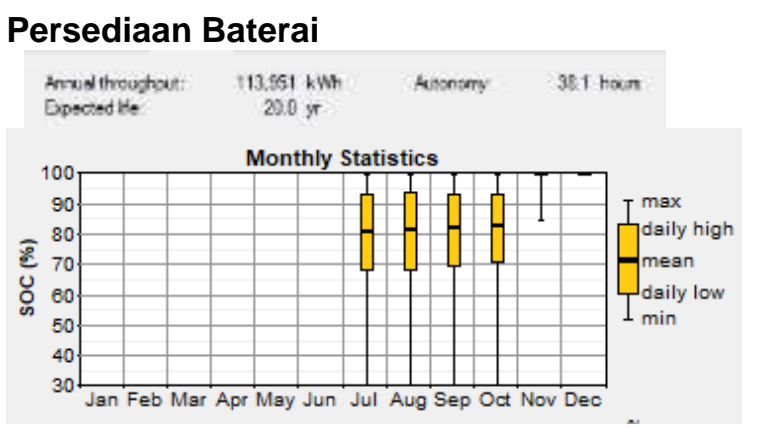

Gambar 11 Persediaan baterai.

Menurut perhitungan HOMER, selama setahun baterai menghasilkan energi sebesar $113.951 \mathrm{kWh} /$ tahun. Perkiraan masa pakai atau umur baterai yaitu selama 20 tahun kemudian akan dilakukan penggantian dengan baterai baru. HOMER juga menghitung cadangan energi yang tersimpan di baterai sebanyak 38,1 jam atau 1,5 hari. Energi cadangan ini akan digunakan untuk mengantisipasi hari-hari mendung saat panel surya tidak beroperasi dengan maksimal.

SoC atau State of Charge merupakan persentase kapasitas baterai yang masih tersedia (tersisa), terhadap kapasitas maksimumnya. Gambar 11 menunjukkan grafik SoC/persediaan baterai bulanan, pada bulan Juli sampai bulan Oktober kapasitas baterai yang masih tersedia berada pada SoC 100\% kondisi max, menunjukkan muatan baterai dalam kondisi penuh. Pada bulan tersebut penggunaan baterai sangat dioptimalkan dalam menyimpan cadangan energi dan menyalurkan energi yang tersimpan dalam baterai untuk memenuhi kebutuhan beban.

\section{Hasil Analisis Sensitivitas}

Masing-masing kategori dilakukan analisis sensitivitas untuk mengantisipasi kemungkinan terjadinya perubahan nilai pada beberapa tahun kedepan, dan setiap perubahan akan menentukan konfigurasi dari sistem. Pada simulasi ini dilakukan 3 kategori untuk analisis sensitivitas yaitu debit air $(500,1.000,1.500 \mathrm{l} / \mathrm{s})$, radiasi matahari $\left(3,96,4,96,5,96 \mathrm{kWh} / \mathrm{m}^{2} /\right.$ day) dan tingkat suku bunga $(4 ; 4,6 ; 5 \%)$ sebagai variabel inputannya.

Kondisi I : Debit air (1.000 I/s), Radiasi Matahari $\left(4,96 \mathrm{kWh} / \mathrm{m}^{2} /\right.$ day $)$, Suku Bunga (4\%)

Kondisi II : Debit air (1.000 I/s), Radiasi Matahari $\left(4,96 \mathrm{kWh} / \mathrm{m}^{2} /\right.$ day $)$, Suku Bunga $(4,6 \%)$

Kondisi III : Debit air (1.000 l/s), Radiasi Matahari $\left(4,96 \mathrm{kWh} / \mathrm{m}^{2} /\right.$ day $)$, Suku Bunga (5\%)

Pada kondisi I, II, dan III, perubahan suku bunga tidak mempengaruhi konfigurasi sistem, yaitu $600 \mathrm{~kW}$ panel surya, 600 baterai bank, 196,2 kW turbin air, dan $300 \mathrm{~kW}$ konverter.

Perubahan suku bunga mempengaruhi biaya keseluruhan sistem (NPC) dan harga jual listrik per kWh (COE). Kenaikan suku bunga mengurangi nilai NPC dan meningkatkan harga jual listrik per kWh.

Kondisi IV : Debit air (500 l/s), Radiasi Matahari $\left(4,96 \mathrm{kWh} / \mathrm{m}^{2} /\right.$ day $)$, Suku Bunga $(4,6 \%)$

Kondisi V : Debit air (1.000 l/s), Radiasi Matahari $\left(4,96 \mathrm{kWh} / \mathrm{m}^{2} /\right.$ day $)$, Suku Bunga $(4,6 \%)$ 
Kondisi VI : Debit air (1.500 I/s), Radiasi Matahari $\left(4,96 \mathrm{kWh} / \mathrm{m}^{2} /\right.$ day), Suku Bunga $(4,6 \%)$

Pada kondisi IV, V, dan VI, perubahan debit air mempengaruhi konfigurasi sistem. Apabila debit air semakin besar, radiasi matahari dan suku bunga cenderung tetap, perubahan konfigurasi terlihat pada daya maksimum yang dihasilkan oleh turbin akan semakin besar.

Perubahan debit air tidak memberikan pengaruh pada biaya keseluruhan sistem (NPC) dan harga jual listrik per kWh (COE).

Kondisi VII : Debit air (1.000 I/s), Radiasi Matahari (3,96 kWh/ $\mathrm{m}^{2} /$ day), Suku Bunga $(4,6 \%)$

Kondisi VIII : Debit air (1.000 l/s), Radiasi Matahari $\left(4,96 \mathrm{kWh} / \mathrm{m}^{2} /\right.$ day $)$, Suku Bunga $(4,6 \%)$

Kondisi IX : Debit air (1.000 I/s), Radiasi Matahari $\left(5,96 \mathrm{kWh} / \mathrm{m}^{2} /\right.$ day $)$, Suku Bunga $(4,6 \%)$

Pada kondisi VII, VIII, dan IX, perubahan radiasi mempengaruhi konfigurasi sistem. Apabila radiasi matahari semakin besar dan debit air tetap, perubahan konfigurasi terlihat pada daya maksimum yang dihasilkan oleh panel surya semakin kecil.

Perubahan radiasi matahari memberikan pengaruh pada modal awal pembangunan sistem, biaya keseluruhan sistem (NPC), dan harga jual listrik per kWh (COE). Panel surya yang dibutuhkan menjadi lebih banyak ketika nilai radiasi matahari semakin kecil. Hal ini dilakukan untuk memaksimalkan penyerapan radiasi matahari agar menghasilkan energi listrik yang maksimal.

\section{KESIMPULAN}

Konfigurasi sistem yang paling optimal adalah $600 \mathrm{~kW}$ panel surya, 600 baterai, 300 kW konverter, dan 196,2 kW turbin air. Konfigurasi sistem tersebut diperoleh berdasarkan nilai NPC terendah yaitu sebesar \$3.123.007 dan nilai COE sebesar $\$ 0,369 / \mathrm{kWh}$. Panel surya berkontribusi sebesar $41 \%$ dan turbin air sebesar $59 \%$ setiap tahunnya dalam mensuplai energi listrik masyarakat desa Kawinda To'i. Analisis sensitivitas dilakukan untuk mengantisipasi kemungkinan terjadinya perubahan ketersediaan sumber daya air dan matahari untuk 10 tahun kedepan. Ketersediaan sumber daya air dan matahari mempengaruhi konfigurasi sistem, produksi energi listrik, nilai NPC, dan harga jual listrik per kWh (COE) yang diperoleh.

\section{DAFTAR PUSTAKA}

[1] Kurniasih, N., Nazir, R., 2015, Analisis Mode Sistem Pembangkit Listrik Tenaga Hibrid Microhydro-Photovoltaic Menggunakan HOMER, Jurnal Nasional Teknik Elektro, Vol. 4, No. 1, p. 30-40.

[2] Arota, A. S., Kolibu, H. S., Lumi, B. M., 2013, Perancangan Sistem Pembangkit Listrik Hibrida (Energi Angin dan Matahari) Menggunakan Hybrid Optimization Model For Electric Renewable (HOMER), Jurnal MIPA UNSRAT, Vol. 2, No. 2, p. 145-150.

[3] Rauf, R., Budiman, Lalan, H., 2017, Studi Penyediaan Daya Listrik Hibrid (PLTMH, Photofoltaik) di Kabupaten Pesisir Selatan, Jurusan Teknik Elektro, Fakultas Teknik \& Perencanaan, Universitas Ekasakti Padang, Padang.

[4] Ibrahim, Rusirawan, D., 2019, Optimalisasi Sistem Mikrogrid Hibrida Berbasis Jarak Pagar menggunakan HOMER, Jurnal TELKOMIKA, Vol. 7, No. 2, p. 268-282.

[5] Arif Febriansyah Juwito, Sasongko PH, T. Haryono, 2012, Optimalisasi Energi Terbarukan pada Pembangkit Tenaga Listrik dalam Menghadapi Desa Mandiri Energi di Margajaya, JURNAL ILMIAH SEMESTA TEKNIKA Vol. 15, No. 1, 22-34

[6] Rajani A, Kusnadi, Darussalam R, 2016, Simulasi Integrasi PV-Biogas Menggunakan Homer Pada Pembangkit Listrik Hybrid On - Grid: Studi Kasus Ponpes Baiturrahman Ciparay Bandung, Prosiding Semnas Prodi Pendidikan Fisika dan Fisika, Fakultas MIPA, Universitas Negeri Jakarta.

[7] Lambert, T., Gilman, P., Lilienthal, P., 2006, Micropower System Modeling with HOMER, National Renewable Energy Laboratory of United States Government, USA.

[8] Archie W. Culp Jr, 1996, Prinsip-Prinsip Konversi Energi, Cetakan Keempat, Erlangga Jakarta, diterjemahkan oleh Darwin Sitompul, Kusnul Hadi 